\title{
Depoimentos de estudantes sobre a Matemática e a Modelagem Matemática: aspectos epistemológicos evidenciados em âmbito escolar
}

\author{
Tiago Emanuel Klüber \\ Universidade Estadual do Centro-Oeste - UNICENTRO \\ tiago_kluber@yahoo.com.br \\ Dionísio Burak \\ Universidade Estadual de Ponta Grossa - UEPG \\ Universidade Estadual do Centro-Oeste - UNICENTRO \\ dioburak@yahoo.com.br
}

Resumo: Este artigo apresenta interpretações de depoimentos escritos por alunos participantes de um projeto de pesquisa desenvolvido com Modelagem Matemática, conforme a perspectiva proposta por Burak (1998). A partir desses depoimentos, tanto os do início como os do final do trabalho, busca-se dialogar com outros pesquisadores da Educação, da Educação Matemática e de outras áreas, no intuito de responder à questão principal: Qual o significado da Matemática e de seu ensino para os alunos? Os resultados evidenciam uma forte tendência à supervalorização da Matemática na perspectiva platônica, implicando na desvalorização do ser aprendiz. Evidenciam, ainda, a possibilidade de um trabalho diferenciado a partir da Modelagem Matemática.

Palavras-chave: Epistemologia, Ensino e Aprendizagem, Educação Matemática, Modelagem Matemática.

\section{Introdução}

Essa investigação com Modelagem Matemática foi desenvolvida na perspectiva proposta por Burak (1987; 1992 e 1998). O principal objetivo foi conduzir as atividades em sala aula através do interesse dos alunos e extrair dados do ambiente. Burak (1992) afirma que a Modelagem "[...] constitui-se em um conjunto de procedimentos cujo objetivo é construir um paralelo para tentar explicar matematicamente, os fenômenos presentes no cotidiano do ser humano, ajudando-o a fazer predições e tomar decisões" (p. 62).

Esse autor propõe cinco etapas para que se desenvolva uma atividade com Modelagem, sendo elas: 1) A escolha do tema; 2) A pesquisa exploratória; 3) O levantamento dos problemas; 4) A resolução dos problemas e o desenvolvimento do conteúdo matemático no contexto do tema; e 5) A análise crítica das soluções. Os desdobramentos dessas etapas serão explicitados nas análises dos depoimentos, por 
entendermos que propiciará uma melhor compreensão do contexto em que inferimos as interpretações do trabalho.

Entretanto, já se pode afirmar que essas etapas não são rígidas, e que, com o desenrolar das atividades, surgem os conteúdos matemáticos sem ser algo prédeterminado como acontece no ensino tradicional. Neste, há um "programa rígido" para ser seguido, que na maioria das vezes "engessa" professores e alunos. Este sistema de ensino é marcado pela 'linearidade', que dificulta a construção do conhecimento e pela repetição mecânica de algoritmos, com a finalidade da memorização de conteúdos prédeterminados no livro didático ou no planejamento do professor.

A pesquisa aconteceu em um colégio estadual na cidade de Guarapuava, PR, para uma turma do Ensino Médio, na qual permanecemos durante quatro meses e utilizávamos uma hora aula por semana, no ano de 2005. Todos os encaminhamentos adotados eram conduzidos pelos princípios da Modelagem, conforme propostos por Burak (1998).

A base de investigação foi qualitativa, pois trabalhamos com inúmeras descrições e dados que são provenientes do ambiente, do fenômeno investigado. Também, ao longo da permanência no colégio, solicitamos alguns depoimentos dos alunos que serviram como base de interpretação para este artigo.

Como referência para a análise, utilizamo-nos de Bogdan e Biklen (1994), que abordam sobre o tema e explicitam que:

A análise de dados é o processo de busca e de organização sistemático de transcrições de entrevistas, de notas de campo e de outros materiais que foram acumulados, com o objetivo de aumentar a sua própria compreensão desses mesmos materiais e de lhe permitir apresentar aos outros aquilo que encontrou. (p. 205).

E ainda, conforme Bogdan e Biklen (1994), a análise de dados pode propiciar a “[...] descoberta dos aspectos importantes" (p.205), conduzindo para o produto final do trabalho. Essas afirmações são entendidas como apropriadas para o objetivo deste artigo. Ou seja, apresentar as interpretações dos depoimentos escritos por alunos acerca de suas opiniões e sentimentos em relação à Matemática, buscando compreender as influências epistemológicas subjacentes ao âmbito escolar. A partir disso, considera-se que esses encaminhamentos permitem contemplar, de forma mais aprofundada, as 
realidades multifacéticas da Escola.

Em concordância com o exposto acima, conduziu-se a análise dos depoimentos através da hermenêutica, que possibilitou-nos penetrar na esfera epistemológica dos conceitos e conteúdos matemáticos, bem como, em alguns aspectos do processo de Ensino e de Aprendizagem que são inerentes à escola, enfim, no próprio "universo" que integra a vida dos participantes da pesquisa. Dessa forma, a análise hermenêutica contribuiu para a interpretação aprofundada das falas, ou ainda, para a "tradução de intencionalidades" focadas. Permitiu compreender o contexto sócio-cultural, no qual os sujeitos estão inseridos.

Por isso, concorda-se com Bicudo (1993) que a hermenêutica possibilita a compreensão do significado da obra humana, seja ela poesia, escultura, arquitetura, textos literários, textos científicos, pré-científicos ou outros. Assim, essa perspectiva é coerente com a nossa maneira de buscar esclarecer profundamente, a partir dos depoimentos dos alunos, as influências epistemológicas subjacentes à Escola, procurando pelos aspectos que o homem experiencia o mundo e o expressa.

Explicitamos que essas interpretações não se restringem ao âmbito da experiência vivida em sala de aula, pois, como citado anteriormente, os dados interpretados são provenientes de um projeto que enfocou o Ensino e a Aprendizagem da Matemática por meio da Modelagem Matemática. Nesse sentido, admite-se que essa discussão acerca das influências recebidas da Educação Formal não está sendo reduzida para uma forma fragmentária. A Escola é um todo que se inter-relaciona pelas diversas variantes sociais e culturais, aproximando-se muito do princípio hologramático ${ }^{1}$ enunciado por Morin (2005a). Vale ressaltar que não se pretende generalizar de forma apressada as depreensões aqui explicitadas. No entanto, considera-se pertinente a opção de fazer essas interpretações.

Pretende-se, então, mostrar neste artigo algumas das diversas influências epistemológicas impregnadas nas falas dos alunos, principalmente aquelas que dizem respeito ao ensino tradicional, fortemente influenciado pelo Platonismo e pelos moldes da Ciência Moderna. Influências que emergiram aos nossos olhos a partir da

\footnotetext{
${ }^{1}$ Holograma é a imagem da física cujas qualidades de relevo, de cor e de presença são devidas ao fato de cada um dos seus pontos incluírem quase toda a informação do conjunto que ele representa. [...] até mesmo a mais modesta célula da epiderme, contém a informação genética do ser global (MORIN, 2005a, p.181).
} 
interpretação e compreensão (hermenêutica), sempre em diálogo com algumas visões teóricas de outros autores que abordam os temas do Ensino, da Aprendizagem, do Ensino Tradicional, da Educação e da Educação Matemática, da filosofia e outras.

\section{Análise hermenêutica dos depoimentos}

A análise foi dividida em três grupos principais que se inter-relacionam, sendo eles: 1) Como os alunos vêem a Matemática? 2) Como os alunos se vêem perante a Matemática? e 3) Como os alunos interpretaram o trabalho com a Modelagem Matemática? A interrogação é a direção que conduz à interpretação por meio da hermenêutica, assim, a nossa questão central foi: Qual o significado da Matemática e de seu ensino para os alunos? Dessa questão, nasceram as três categorias, pois buscamos os significados da Matemática, da Educação e da Educação Matemática, da pessoa na visão de autores, inclusive na tradição filosófica.

$\mathrm{Na}$ medida em que os trechos das falas dos alunos são apresentados, em seguida entramos com a interpretação dos significados desses trechos. Assim, a forma de abordagem hermenêutica permeará todo o texto.

\section{A Matemática}

Sobre o primeiro grupo, (Como os alunos vêem a Matemática?), os educandos em depoimento escrito argumentaram que essa disciplina é a mais importante e que está presente em praticamente todas as demais disciplinas, uma espécie de panmatematismo. Tais apontamentos se evidenciam nos seguintes trechos, de depoentes diversos: "Se pensarmos bem a matemática faz parte de todas as outras matérias [...]", "[...] a matemática está em quase tudo [...]" e "[...] a nossa vida está resumida na matemática, tudo o que você faz inclui ela." (SIC).

Os depoimentos também evidenciaram o caráter mítico e místico conferido à Matemática, muito próximo às concepções "platônicas" de conhecimento. Caráter que causa um distanciamento da Matemática da vida cotidiana, que parece não fazer parte do nosso mundo humano, como por exemplo: "[...] um bicho de sete cabeças.", "[...] deveríamos trabalhar na sala de aula mais problemas que envolvam as situações apresentadas nosso dia-a-a-dia" e "[...] algumas matérias parece inútil, pois não vejo utilidade no dia-a-dia." (SIC). 
Não que defendemos a Matemática como pura utilidade, apenas com finalidades práticas, todavia, não podemos concebê-la no contexto escolar, destituída de sentido. E, o depoimento que mais evidencia esse misticismo é o seguinte "[...] devido o 'sistema' faz uma defasagem em certas áreas, cujo são 'mistificadas' isso faz com que certas pessoas mesmo sem o devido contato pré-julguem como difícil." (SIC).

Em decorrência das explanações acima, percebeu-se que as idéias acerca da Matemática, apresentadas pelos alunos, são fruto de uma construção histórica de longa data, pois essa disciplina tem procedimentos lógicos e formais desde Platão, passando por Descartes e Leibniz, mesmo que nessa época, a Matemática fosse formada apenas pela Aritmética e, posteriormente, apenas pela Geometria Euclidiana.

Para esses pensadores, as idéias matemáticas eram vistas apenas como construção da razão e a mais confiável de todas. Essas idéias perduram por séculos e permanecem até hoje em praticamente toda construção científica da civilização ocidental. (PLATÃO, 1986).

É possível elucidar aspectos dos depoimentos dos alunos, recorrendo à obra Platão: A República - Livro VII - quando o Filósofo Sócrates trava um diálogo com Glauco acerca da Aritmética (Matemática) dizendo: "Que bem poderia tratar-se de uma das ciências que procuramos, que conduzem naturalmente, a alma à inteligência".

O comentário da nota sobre este trecho é sugestivo e explica "Que preparam a inteligência para conhecer, sozinha, sem o auxílio dos sentidos, as realidades do mundo inteligível” (p. 59). Esse mundo inteligível mundo das Idéias (essências), reflete a idealidade concebida aos entes matemáticos, idealidade que ainda está presente na realidade escolar, pelo menos na maneira de os alunos se expressaram.

Na mesma obra, também concebe que a Matemática "é a ciência que melhor descreve a existência das realidades verdadeiras e não sensíveis" (PLATÃO, 1986, p. 28). E mais, "A matemática nos auxilia a conceber a existência e a essência - quer dizer, a natureza - das realidades inteligíveis (as idéias)" (p.29). Caracterizando uma realidade perfeita, que somente poderiam ter acesso, aqueles que possuíssem prédisposição para aprender a Matemática pela Matemática, uma disposição natural de seu espírito.

A razão, para essas correntes Filosóficas resguardadas as suas particularidades, enseja que "O Ideal do conhecimento é o conhecimento necessário, o qual nos fornece 
as verdades da razão, que são inatas, virtualmente impressas e independentes da experiência” (MENEGHETTI; BICUDO, 2003, p. 62). E, também, “... aprender Matemática consiste em fazer acordar a Matemática que está latente em cada um de nós" (LEIBNIZ apud MENEGHETTI; BICUDO, 2003, p. 62).

Essa influência epistemológica presente na Escola, nas aulas de Matemática, fica evidente nos currículos escolares, nas apresentações dos programas didáticos, nos livros didáticos e sob formas de avaliação ainda muito utilizadas na atualidade. Isso, pelas "falas" dos alunos, que referenciaram o caráter mítico e até mesmo místico dessa disciplina.

Gostaríamos de lembrar que não temos a intenção de desconsiderar as contribuições desses pensadores, sem as quais não se teria chegado a tão prodigiosos feitos em nossa civilização. Principalmente no aspecto do rigor, já incitado e estimulado por Platão, quando fundou a "Academia" em oposição às simples opiniões emitidas pelos sofistas ${ }^{2}$.

Contudo, as idéias fragmentárias e particionadas que diminuem a importância do sujeito, do ser, voltando-se apenas para um objeto (conteúdo matemático), prejudicam, e muito, o ambiente escolar. E, diante disso, entendemos que as idéias matemáticas se tornaram estranhas aos que a elas têm acesso e, por consequiência, parecem tão difíceis e sem conexão com a vida real.

Interpreta-se que tais influências de pensamento ainda são muito fortes e presentes em todo o 'universo' escolar e, principalmente, no ensino e na aprendizagem de Matemática. Não é sem motivo que os alunos apresentam-na com tantas características ideais, mesmo sem a clareza da existência dessas correntes filosóficas provenientes e consideradas releituras do idealismo platônico. Com isso, reforçando a incoerência em se dar mais importância para um falso objeto da Educação, que seria apenas a Matemática, do que para o sujeito, o Educando, o Professor. Sem considerar a relação dialógica entre sujeito e objeto que se constituem simultaneamente.

Quando se fala em Educação, e nesse caso em Educação Matemática, deve-se considerar os sujeitos dela (professor/aluno) e o ambiente em que se relacionam, uma vez que não há ensino e aprendizagem sem pessoas. Dessa maneira, identifica-se que os alunos estão sendo simplesmente informados e, não formados, pois a repetição de

\footnotetext{
${ }^{2}$ Conferencistas itinerantes, na maioria das vezes itinerários da Sicília, tinham domínio da palavra ou arte da retórica (PLATÃO, 1986, p. 13). Porém, travavam discursos sem aprofundamento, frutos da opinião.
} 
fórmulas não conduz para um aprendizado significativo.

Alguns depoimentos reforçam a nossa afirmação acerca da superposição dos conteúdos matemáticos sobre a compreensão dos alunos: "Pois se o professor fica só lá na frente explicando no quadro, acaba se tornando uma rotina irritante e chata, e a matemática tem várias maneiras de se aprender.", e "o ensino é um pouco fraco e a vontade de aprender as vezes fica um pouco monótono ouvir o professor." (SIC).

Provavelmente, a maioria dos professores que ministraram a disciplina de Matemática, adquiriu em sua formação (sem a devida consciência) parte das influências epistemológicas de um ensino por repetição e reprodução. Ensino em que o professor é a peça principal e os alunos são inseridos passivamente no processo de se ensinar e aprender Matemática, apenas como ouvintes. Caracteriza-se, assim, o ensino bancário (FREIRE, 1997).

Esse tipo de ensino que somente informa, causa o problema da dispersão, uma vez que as informações só têm significado "[...] quando se transformam em instrumento de interlocução, de diálogo (interior) multifacético e multidimensional". (SANTOS, 2004, p. 20). Diálogo que fica prejudicado pela falta de significado. Esse tipo de ensino se caracteriza bem no seguinte excerto: "Sempre foi bem trabalhada em sala de aula, a explicação sempre foi suficiente para realizar exercícios, ir bem nas provas, etc. Porém, não foi suficiente para gravarmos o conteúdo por muito tempo." (SIC).

Nessa perspectiva, entende-se que se faz necessário romper, mesmo que lentamente, com essas influências educacionais que também são fruto da concepção de Ciência Moderna (Cartesianismo). Faz-se urgente que se contrarie a lógica clássica que não aceita a dualidade e os paradoxos. Por decorrência, depreende-se que: o que deveria facilitar, pois se tornou "simples", dificulta ainda mais a aprendizagem, pois essa partição e simplificação, propostas pela Ciência Moderna e que estão presentes na Matemática e em seu ensino, acabam por deslocar o homem da vivência complexa. A citação seguinte elucida o que se quer dizer: "O corpo não dança, a razão não dança. $O$ homem dança". (FONTANELLA apud SANTOS, 2004, p. 21).

Sabe-se que a Matemática escolar é formada por uma série de axiomas, leis, estruturas e entes concebidos como ideais - características atribuídas à Ciência Matemática. Porém, não concordamos que ela deva ser ensinada como um fim em si mesma, ou como ideal. Primeiro, porque se torna muito difícil o acesso a ela e, segundo, 
quando desconsidera todo o processo de construção dessa disciplina, ela se torna mistificada e mitificada, reforçando as afirmações anteriores e se encaminhando pelos ideais platônicos e cartesianistas. Tal característica aparece no trecho a seguir: “[...] pois como alguém disse matemática é uma ciência exata e qualquer vírgula, sinal, ponto fora do lugar você erra a conta inteira.” (SIC).

Outro aspecto a ser destacado perpassa a reprodução social, quando se ensina qualquer coisa descontextualizada se incitam à alienação e ao desinteresse. As pessoas não têm como dar respostas claras sobre as diversas realidades que se apresentam a elas. Com relação à Matemática como instrumento de cidadania, Skovsmose (2004) infere que "Seu papel é crucial e, portanto, deve ser considerado na interpretação de uma vasta gama de fenômenos sociais". (p. 31)

Procuramos, também, tecer um diálogo inicial neste artigo com a “[...] complexidade que coincide com uma parte de incerteza, seja proveniente dos limites do nosso entendimento, seja inscrita nos fenômenos" (MORIN, 2005b, p. 35). Isso, no sentido da organização dos conteúdos matemáticos, de suas aplicações, das interações que os indivíduos fazem com essa disciplina e com outras.

Atualmente, a Matemática é considerada a disciplina da certeza e, por isso, compreendemos esse diálogo com a complexidade válido, para que não ocorra a concretização desse pensamento estagnado e petrificado, que não é verdadeiro. Inclusive porque existem outras Matemáticas, denominadas "Etnomatemáticas" de acordo com D’Ambrósio. Essa Matemática escolar é uma Etnomatemática originária da Europa que recebeu influências indiana e islâmica (D'AMBRÓSIO, 2004). Assim, temse mais um motivo para que não seja imposta, para que o professor leve em consideração a 'bagagem' que cada educando possui no que concerne à cultura e suas raízes comunitárias.

Encerramos essa categoria com a "fala" de um dos alunos, pois a compreendemos como uma verdade esclarecedora, parte do mundo-vida desse aluno, presente em seu mundo-horizonte, e também, constitui-se em um invariante a respeito do Ensino de Matemática atualmente disseminado: talvez "[...] o difícil não seja aprender Matemática mas desfazer os mitos que a cercam.” (SIC). 


\section{Os alunos e a Matemática}

Com relação ao segundo grupo de análise, (Como os alunos se vêem perante a Matemática?), vários depoimentos indicam para o desgosto dos alunos e para a atribuição de culpa em relação à dificuldade de aprendizagem da matemática. São eles: a Matemática "[...] é um pouco complicada, principalmente para quem não gosta muito", "penso que não levo jeito para isso (a matemática)", "Eu acho a matemática muito chato.", "[...] não sou uma pessoa chegada nisso [...] a causa de não intendermos mto, é falha nossa", ou ainda, "[...] só não consigo aprende, mas por falta de inteligência." (SIC).

Compreende-se que os alunos se tornam condicionados às idéias que são repassadas em relação à Matemática, por este motivo, vários deles depuseram que o problema da aprendizagem é totalmente deles. Interpretamos que as dificuldades de aprendizagem e de interesse são rejeições advindas de diversos traumas, os depoimentos que se referiram ao ensino elucidam essa afirmação: “[...] até hoje não gosto daquela professora (do primário), pois ela era muito rústica" e, a Matemática "[...] sempre foi de longe matéria que sempre me causou mais pânico." (SIC).

Sobre esse assunto, Nicola (1999) afirma:

O homem é autor de sua própria trajetória, mas não podemos esquecer que, enquanto ser de relação, sua caminhada, em busca da autonomia e autorealização, se dá através da interação constante que faz com o meio ambiente e com as pessoas significativas de sua vida. (p.81).

Os traumas referenciados nos depoimentos, provavelmente são provenientes de pessoas significativas, como o professor, que tem um forte papel social e é, muitas das vezes, o causador da aversão que os alunos têm em relação à Matemática, ou ainda, os pais, que antes mesmo de os filhos adentrarem à Escola, falam da Matemática como um "Bicho de Sete Cabeças".

Retornando a questão do professor, cabe também parafrasear o que Nicola (1999) diz: é fundamental que o professor tenha em sua formação, a capacidade de conhecer o sujeito que aprende suas funções psíquicas e suas particularidades, que precisam ser respeitadas e percebidas como potencialidades a serem descobertas. E, a partir delas, criar uma interação educacional. Não que o professor deva tornar-se um psicólogo, ou venha à 'piscologizar' as situações educacionais, entretanto, isso não o 
impossibilita de ter uma postura atenta e crítica.

Alguns alunos afirmaram gostar da Matemática, pelo fato de compreendê-la: "[...] acho que comecei a gostar quando comecei a entender", "[...] eu gosto muito dela, é a matéria que me dou melhor, porque desde pequeno eu adorava fazer cálculos $[\ldots] "$ (SIC).

Os alunos que se referem à Matemática como a melhor disciplina de todas, se bem entendida, confirmam que se o aluno for olhado da maneira correta poderá, com toda certeza, ter domínio, mais do que simplesmente de conteúdos e sim de conhecimentos. Porém, há que se lembrar que algumas crianças se adaptam mais facilmente ao sistema de reprodução e, o fato de gostar da Matemática não implica diretamente em aprendizagem a partir do significado, mas sim da repetição.

\section{Os Alunos e a Modelagem Matemática}

Antes de explicitarmos as depreensões sobre o que os alunos perceberam do trabalho com a Modelagem Matemática, abordaremos sucintamente o que consiste as etapas descritas na introdução deste artigo, sendo elas: 1) escolha do tema; 2) pesquisa exploratória; 3) levantamento dos problemas; 4) resolução dos problemas, onde se desenvolve o conteúdo matemático; e 5) análise crítica das soluções.

Escolha do tema - é o momento em que o professor apresenta aos alunos alguns temas que possam gerar interesse ou os próprios alunos sugerem um tema. Esse tema pode ser dos mais variados, uma vez que não necessita ter nenhuma ligação imediata com a Matemática ou com conteúdos matemáticos e sim com o que os alunos querem pesquisar. Já nesta fase é fundamental que o professor assuma a postura de mediador, pois deverá dar o melhor encaminhamento para que a opção dos alunos seja respeitada.

Pesquisa exploratória - escolhido o tema a ser pesquisado, encaminha-se os alunos para a procura de materiais e subsídios teóricos dos mais diversos que possam conter informações e noções prévias sobre o que se quer desenvolver/pesquisar. A pesquisa pode ser bibliográfica ou pode contemplar um trabalho de campo, fonte rica de informações e estímulo para a execução da proposta.

Levantamento dos problemas - de posse dos materiais e da pesquisa desenvolvida, incentiva-se os alunos a conjeturarem sobre tudo que pode ter relação com a Matemática, elaborando problemas simples ou complexos que permitam 
vislumbrar a possibilidade de aplicar ou aprender conteúdos matemáticos, isso com a ajuda do professor que não se isenta do processo, mas se torna o "mediador" das atividades.

Resolução dos problemas e o desenvolvimento do conteúdo matemático no contexto do tema - nesta etapa, busca-se responder os problemas levantados com o auxílio do conteúdo matemático, que pode ser aplicado de uma maneira extremamente acessível, para posteriormente ser sistematizado, fazendo um caminho inverso do usual, pois se ensina o conteúdo para responder às necessidades surgidas na pesquisa e no levantamento dos problemas concomitantemente.

Análise crítica das soluções - etapa marcada pela crítica, não apenas da matemática, mas de outros aspectos, como a viabilidade das resoluções apresentadas, que muitas vezes são resolvíveis matematicamente, mas inviáveis para a situação estudada e para situações reais. Não é necessariamente a análise de um modelo, mas dos conteúdos, dos seus significados e no que eles podem contribuir para a melhoria das ações e decisões enquanto pessoas integrantes da sociedade e da comunidade em que participam.

Tratando da categoria, (Como os alunos interpretaram o trabalho com a Modelagem Matemática?), os depoimentos revelaram mais uma vez que os alunos estão condicionados à atual estrutura educacional, o que é algo 'natural' depois de tantos anos de vida em âmbito escolar, exemplos dessa situação são estes: "[...] Pensei que era inrolação", com relação ao método uma aluna disse: "honestamente ele deveria ser melhor planejado, já com algo determinado [...] tenho certeza que grande parte achou que isso era matar aula." (SIC). A partir disso, fica clara a visão imediatista dos alunos, pois quando se discutia quais eram seus interesses de pesquisa e eles eram orientados para a pesquisa exploratória, entenderam que isso seria "matar" aula, quando na verdade a principal idéia era, a partir dos seus interesses, incentivá-los à autonomia.

Consideramos que essa visão dos alunos prejudica o trabalho cooperativo e em grupo, que se tornam difíceis quando não há clareza dos participantes sobre a sua posição de ser ativo ou passivo no processo.

Pode-se afirmar isso em consonância com o que Santos (2004) diz: "As técnicas didáticas foram concebidas como neutras e elaboradas com a pretensão de tornar 'objetivo' um relacionamento que, por natureza, é subjetivo” (p. 35). Por conseguinte, a 
intersubjetividade fica prejudicada pela falta de comunicação efetiva entre professor e aluno, ou seja, há a ausência de diálogo, o não reconhecimento do outro.

Por isso, a estranheza dos alunos em relação a um trabalho que envolve um pouco mais de intersubjetividade e de ações autônomas, sem a imposição de ser sempre objetivo, como por exemplo: o professor falar, o aluno ouvir, copiar e posteriormente responder (avaliação). Isso porque na Modelagem, conforme aqui concebida, não nos importa tanto o produto, (avaliação de conteúdos), mas sim o processo. Entretanto, nossos alunos estão acostumados com a "pedagogia dos resultados e do conteúdo" (SANTOS, 2004, p.34), isso em decorrência da influência sócio-cultural intrínseca à escola.

$\mathrm{O}$ fato de alguns alunos acharem as aulas demoradas e pouco produtivas tem um viés imediatista. Eles estão acostumados a receber informações como se elas fossem depósitos em conta bancária (FREIRE, 1997). Pensam que é pelo acúmulo de informações que se "sairão bem", pois os alunos participantes do projeto, em sua maioria, pretendiam prestar vestibular no ano seguinte, e por este motivo, objetivavam 'ver' a maior quantidade possível de conteúdos. Ressaltamos que tais alunos são em grande parte aqueles considerados os 'melhores' da turma, aqueles que com certeza entendiam a Matemática pela própria Matemática.

Contrariamente, na Modelagem acontece a relativização dos conteúdos matemáticos e não a objetivação, aplicação direta e descontextualizada, contrapondo-se aos ideais platônicos, que buscavam a verdade como conhecimento e certeza absoluta, se valendo da Matemática. (PLATÃO, 1986). O trabalho com a Modelagem sugere outros encaminhamentos e mais interação entre o professor e o aluno, assim, ela permite 'quebrar' o ritmo das aulas de Matemática, que são fortemente marcadas pela exposição excessiva de conteúdos. Percebe-se essa dinamicidade da Modelagem, pelos seguintes excertos "[...] conseguimos ver algumas coisas de outra forma" e; "[...] conseguimos aprender a matéria de Matemática de um modo diferente, sem aqueles processos rotineiros de sempre." (SIC). 
O processo de ensino e a aprendizagem com a Modelagem Matemática tende a romper com esses parâmetros de um conhecimento petrificado, universalizado e descontextualizado, advindos do modelo cartesiano ${ }^{3}$. Principalmente porque trabalha adjacente às situações cotidianas, implicando a problematização, a qual pode estar associada ao que Santos (2004) explica sobre a atividade docente em sala de aula, sob a ótica do pensamento complexo, ou seja, "Estar em sala de aula significa uma contínua superação por meio da problematização e da apropriação do conhecimento" (p. 36).

Com a Modelagem, pretendia-se fazer que os educandos sentissem a necessidade de produzir seus conhecimentos, manter um diálogo constante com o professor, o conteúdo, os saberes do cotidiano, dentre outros saberes escolares. O respeito às particularidades e as diferenças de cada um sempre se fizeram presentes, conforme Klüber (2005), o que nos conduz a concordar com Santos (2004), que "[...] a função do docente passa a ser a de um facilitador de diálogos com os saberes [...]" (p.54), clareando que o conhecimento não se transfere, mas sim, se constrói.

\section{Algumas considerações}

Buscou-se, nesse artigo, analisar os depoimentos dos alunos acerca da Matemática escolar e do trabalho desenvolvido com Modelagem Matemática, para, a partir disso, explicitar algumas faces epistemológicas presentes no âmbito escolar.

Discutiram-se como as influências do pensamento Platônico e da Ciência Moderna ainda permeiam a nossa sociedade, afetando diretamente as metodologias, os currículos, estruturas em geral e a própria vida dos alunos, mesmo sem estes terem a clareza dessas influências.

Procurou-se, ainda, mostrar como a Modelagem pode ser um instrumento de ruptura frente a essas correntes filosóficas que ainda marcam o âmbito escolar profundamente. Justamente porque na Modelagem, conforme concebida por Burak (1998), se oportunizam delineamentos diferenciados, nos quais professor e aluno participam da construção do conhecimento interagindo com o seu ambiente e com a 'bagagem' que cada um traz consigo de suas experiências e realidades.

Por fim, esperamos que as depreensões aqui explicitadas colaborem para que professores de Matemática percebam de maneira diferente as suas aulas e, por

\footnotetext{
${ }^{3}$ Cartesiano não se refere apenas ao método de Descartes, quando falo cartesianismo, referimo-nos a uma corrente filosófica de inúmeros pensadores da Modernidade, Newton, Leibniz e ao próprio Descartes.
} 
conseguinte, consigam romper com a forma tradicional de ensino, que prima pela repetição e hiper-valorização da Matemática. Se nos permitem, podemos sugerir um caminho? A Modelagem Matemática.

\section{Referências Bibliográficas}

BECKER, F.. A epistemologia do professor: o cotidiano da escola. Petrópolis: Vozes, 1993.

BICUDO. M. A. V.. A hermenêutica e o trabalho do professor de matemática. Cadernos da Sociedade de Estudos e Pesquisa Qualitativos. v. 3, n. 3, 1993, p. 6194.

BOGDAN, R.; BIKLEN, S.. Investigação qualitativa em educação: uma introdução à teoria e aos métodos. Porto: Porto Editora, 1994. (Coleção Ciências da Educação).

BURAK, D.. Modelagem matemática: uma alternativa para o ensino de matemática na $5^{\text {a }}$ série. 1987. Dissertação (Mestrado em Educação Matemática). Universidade Estadual Paulista, Rio Claro, 1987.

Modelagem Matemática: ações e interações no processo de ensinoaprendizagem. 1992. Tese (Doutorado em Educação). Universidade Estadual de Campinas, Campinas, 1992.

Formação dos pensamentos algébricos e geométricos: uma experiência com modelagem matemática. Pró-Mat. - Paraná. Curitiba, v.1, n.1, p.32-41, 1998.

D'AMBRÓSIO, U.. Um enfoque transdisciplinar à educação e a história da matemática. In: BICUDO, M. A.V.; BORBA, M. de C.. Educação Matemática: pesquisa em movimento. São Paulo: Cortez, 2004, p. 198-212.

FREIRE, P.. Pedagogia da Autonomia: saberes necessários à prática educativa. São Paulo: Paz e Terra, 1997.

KLÜBER, T. E.. Modelagem Matemática: uma experiência concreta. In: IV Conferência Nacional sobre Modelagem e Educação Matemática - IV CNMEM. 2005. Anais... Feira de Santana: UEFS - 1CD-ROM.

MENEGHETTI, R. G.; BICUDO, I.. Uma discussão sobre a constituição do saber matemático e seus reflexos na Educação Matemática. Bolema. Ano 16 n. 19, março 2003, p. 58-72.

MORIN. E.. O desafio da Complexidade. In: Ciência com Consciência. trad.

Maria D. Alexandre e Maria Alice Sampaio Dória. Rio de Janeiro: Bertrand Brasil, 2005a, p. 175-195.

MORIN, E.. Introdução ao pensamento complexo. trad. Eliane Lisboa. Porto Alegre: Sulina, 2005b.

NICOLA, P. I.. Formação psicológica do professor. In: LAMPERT, E.. Educação para a cidadania. Porto Alegre: Sulina, 1999, p. 79-95.

PLATÃO. A República: Livro VII. apres. e comen. Bernard Piettre. pref. Pierre Aubenque. trad. Elza Moreira Marcelina. Brasília: Ed. UNB, 1986.

SKOVSMOSE, O. Matemática em ação. In: BICUDO, M. A. V.; BORBA, M. de C.. (Orgs.). Pesquisa em Educação Matemática: pesquisa em movimento. São Paulo: Cortez, 2004, p. 30-54.

SANTOS, A.. Didática sob a Ótica do Pensamento Complexo. Porto Alegre: Sulina, 2004. 